\title{
Comparative effects of posture on pressure and shear at the body-seat interface
}

\author{
Douglas A. Hobson, PhD \\ School of Health and Rehabilitation Sciences, University of Pittsburgh, Pittsburgh, PA 15238
}

\begin{abstract}
This study considers the effects of seated posture and body orientation on the pressure-distribution and surface shear (tangential) forces acting at the bodyseat interface. Nine postures typically assumed by wheelchair users were studied. Comparisons were made within and between two study groups, made up of 12 subjects with spinal cord injuries (SCI) and 10 nondisabled subjects. Both interface pressure and the surface shear were measured simultaneously in each of nine reproducible, seated postures. The same seat cushion was used for all trials. The Oxford Pressure Monitor, a pneumatic cell device, was used to measure and record the interface pressures. Instrumentation for measuring and recording the surface shear force was constructed specifically for the study. Analysis consisted of statistically comparing changes in pressure values and shear forces derived from eight sitting postures with reference to values recorded in a defined neutral sitting posture. The pressure-distribution findings suggest that in the postures studied $\mathrm{SCI}$ subjects have maximum pressures that are higher than nondisabled subjects in all postures, ranging from $6 \%$ to $46 \%$ depending on the posture. Maximum pressures can be reduced by postural changes: forward flexion to $50^{\circ}$, $-9 \%$; backrest recline to $120^{\circ},-12 \%$; and, full body tilt, $-11 \%$. On average, the SCI group members have peak pressure gradients (PPG) that are 1.5 to 2.5 greater than the nondisabled group. The maximum reduction in $\mathrm{PPG}$ occurred at backrest recline of $120^{\circ},-18 \%$. Tangential shear force acts at the body-seat interface in all nine postures studied. Extrapolation of results suggests that full-body tilt to approximately $25^{\circ}$ reduces the surface shear force to near zero. In contrast, a backrest-
\end{abstract}

Address all correspondence and reprint requests to: Douglas A. Hobson, PhD, School of Health and Rehabilitation Sciences, University of Pittsburgh, 915 William Pitt Way, Pittsburgh, PA 15238. only recline of $20^{\circ}$ causes a $25 \%$ increase in the surface shear force. These results suggest that caution must be taken when using nondisabled subjects as surrogates for people with SCI because of the inherent differences between the groups. Also, researchers and clinicians should recognize that posture and body orientation in space are additional variables that can have a profound effect on the interaction between a seated person and his or her supporting surface.

Key words: body-seat interface, pressure distribution, spinal cord injury, surface shear force.

\section{INTRODUCTION}

Studies conducted over the past several decades have confirmed that the incidence and related costs of pressure-sore treatment remain a major health problem $(1,2,3)$. Support of body weight while lying, sitting, or standing necessitates the transmission of internal stabilizing forces via the supporting tissues to external support surfaces. This results in tissue-distorting forces being transmitted to underlying soft tissues. Excessive or prolonged application of distorting mechanical forces can result in vascular occlusion, ischemia with eventual necrosis and the onset of a "pressure sore" $(4,5)$. The onset usually occurs in the deeper tissues and then migrates toward the surface $(6,7)$.

Both clinical and research evidence, although conflicting and inconclusive in several areas, are strongly biased toward excessive and/or prolonged application of surface pressure as being the predominant causative factors in pressure-sore formation. 
Journal of Rehabilitation Research and Development Vol. 29 No. 4 Fall 1992

Although at least one investigator has questioned the primacy of pressure as a causal factor in pressure-sore formation (8), the fact remains that there is a dearth of research evidence suggesting any more dominant factor than interface pressure.

There is also compelling evidence that factors in addition to pressure are contributors and must also be considered when attempting to fully understand the pressure-sore phenomenon. Studies have implicated factors such as shear stress (9), impact loading of tissue (5), elevated temperature and humidity $(10,11)$, age, nutritional status, general health, activity level (12), deformity, posture and postural change $(13,14)$, body stature $(15)$, and psychological deficits. Crenshaw and Vistnes (16), in their review of pressure sore research, effectively highlighted the studies and current thinking on the etiology and related factors that can predispose a person to pressure-sore formation.

Numerous research techniques and devices have been developed in an attempt to quantify the interface pressure. Mooney (17) described the design of a flexible polyvinylchloride (PVC) airtight pneumatic cell with follow-up clinical trials. Fernie (18) did an exhaustive analysis of the interface technology used before 1973. Ferguson-Pell (19) outlined the design criteria for an ideal interface-pressuremeasurement transducer for measuring pressure differences across nonuniform surfaces. Garber and Krouskop (15) described the design and clinical use of a $12 \times 12$-matrix transducer device, commercially termed the Texas Interface Pressure Evaluator (TIPE). Bader (20) and Bader and Hawkins (21) reported on the development of the Oxford Pressure Monitoring (OPM) device that built on the previous work of investigators such as O'Leary and Lyddy (22), who first described the principle upon which the OPM is based.

The focus of research and clinical efforts with the cited measurement tools has been to quantify the interface pressure between a seated person and the supporting substructure, usually a seat cushion in a wheelchair. Efforts have been made to establish absolute threshold values above which seated persons are likely to be at risk of pressure-sore formation. Other applications have attempted to make comparisons between various supporting materials and related commercial products to guide improved product selection. Studies by Reddy et al. (23) and Guthrie (24) have emphasized the difficulty in obtaining and accurately interpreting absolute pressure values, especially when used in nonplanar environments consisting of materials with compliance properties significantly different from human soft tissue. Reddy et al. (23) came to the conclusion that comparative values rather than absolute values are more likely to be meaningful, especially when the interface materials can be kept constant and the materials have mechanical properties approaching those of human buttock tissue.

Review of the research literature indicates that little attention has been given to the effects of posture and deformity on pressure distribution at the seat interface or to how those effects might vary between nondisabled and people with a spinal cord lesion. Zackarkow (14) strongly emphasized the importance of these factors and the need for research verification of clinical observations.

Over the years, both researchers and clinicians have indicated a concern about the effects of shear stress acting at the body-support interface. Guttmann (25) emphasized the importance of distinguishing between purely vertical pressure and shear stress: "Shear stress is much more disastrous for it cuts off larger areas from their vascular supply." Reichel (26) expressed an opinion that raising the head of a hospital bed by even a few inches was capable of producing sufficient shear force over the sacral area to deprive large tissue areas of blood supply. Bennett et al. (9) came to the conclusion that combined pressure plus shear particularly promotes occlusion. The value of pressure necessary to produce occlusion can be nearly halved when accompanied by sufficient shear. Other investigators have also stressed that tissue deformation is a major etiological factor in ulcer formation $(8,27,28)$. Chow and Odell (29) made the point that shear stress is involved in uniaxial pressure, localized pressure, and any nonuniform pressure distribution or pressure that causes tissue distortion.

In addition to shear stresses induced by the normal pressure, there are also shear stresses caused by forces that are acting tangential to the support surface, that is, friction forces. Very little progress has been made toward the measurement and use of frictional shear force information in clinical decision making (16). This is due, in part, to the complexity of the interface shear-stress phenomenon when viewed in its entirety. However, if one differentiates between the types of shear stresses, normally in- 


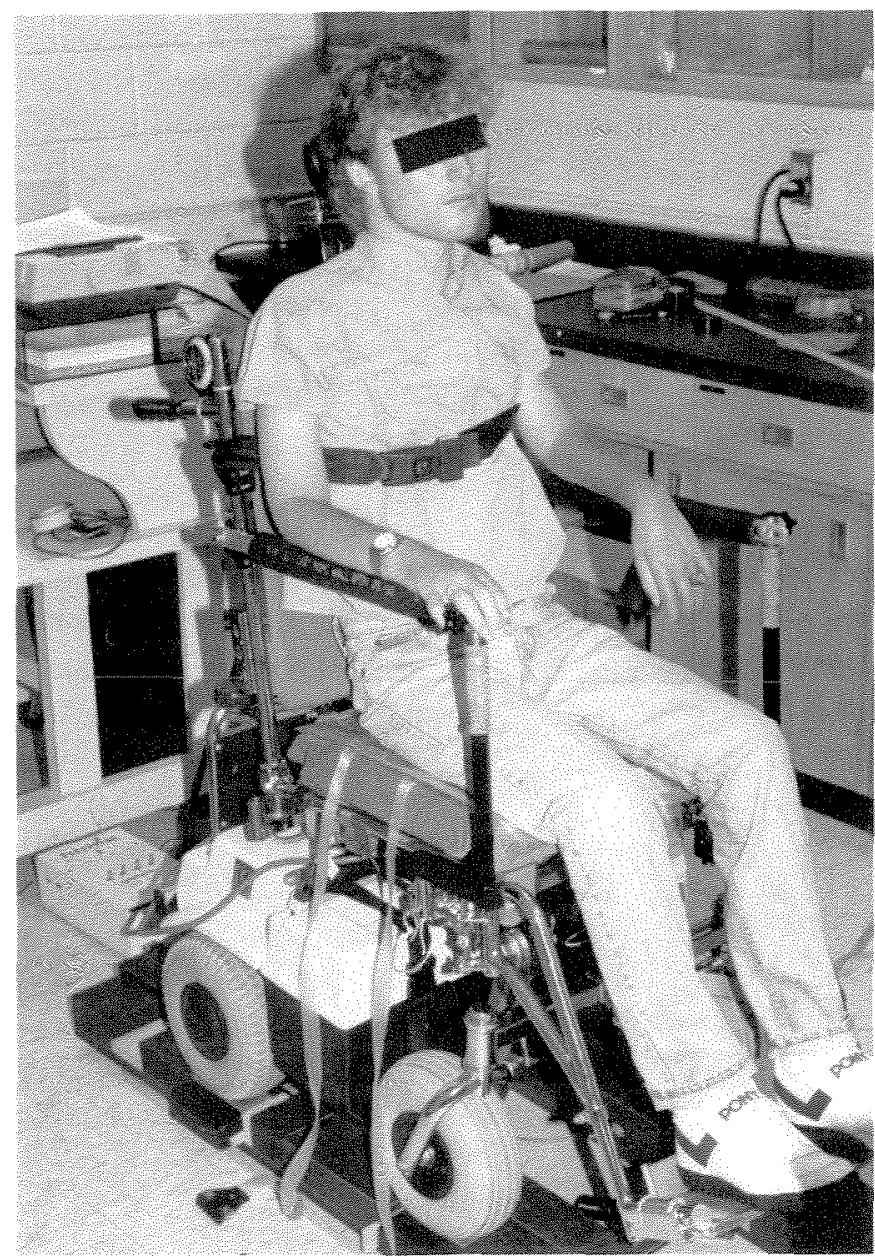

Figure 1 .

Disabled subject positioned on the $\mathrm{BPC}$ in neutral position (arms are placed on lap during pressure- and shear-recording sessions).

duced and tangentially induced, one can conceive of practical methods to measure the simpler tangentially induced shear (TIS) forces. Adoption of TIS measurements as a practical tool could provide clinicians with information about a variable, in addition to the pressure variable, that should be factored into clinical decision-making processes. However, it should be stated that the manner in which the shear- and normal-force components interact within the tissues will not be illuminated by this rather direct and simplistic approach.

In summary, this study has investigated the effects of changes in sitting postures and body orientation in space on interface pressure distribution and on TIS that acts at the body-seat interface.

\section{OBJECTIVES}

The objectives of this study were: 1) to identify pressure-distribution differences that may exist within and between the nondisabled and spinal cord injured (SCI) populations and to determine how the distributions may be affected as a result of deformity and/or alterations in sitting postures; and, 2) to investigate the manner in which TIS forces change with body posture, both within and between an SCI group and a nondisabled control group.

\section{METHOD AND MATERIALS}

Ten nondisabled and $12 \mathrm{SCI}$ subjects participated in the study. The nondisabled group consisted of six males and four females with a mean age of 39.3 years and a range from 28 to 57 years. Mean body weight was $68.6 \mathrm{~kg}$ with a range of from 50 to $95.5 \mathrm{~kg}$. All subjects in this group reported no previous impairments of spinal or pelvic movement.

All 12 SCI subjects were diagnosed as having complete lesions of their spinal cords for at least 5 years. The sample contained 10 males and 2 females: 7 paraplegic and 5 quadriplegic. Mean age was 40.9 years with a range of 25-66 years. Mean body weight was $59.8 \mathrm{~kg}$ with a range of $39-74.2 \mathrm{~kg}$. The mean number of years since injury was 19.5 with a range of 6-54 years. In general, the subjects in the SCI group were all active individuals living in the community who regularly use a wheelchair.

Nine typical wheelchair sitting postures, as defined below, were studied. A specially designed body-positioning chair (BPC), using a Fortress model FS655 (Fortress, Inc.) with a powered recliner as the base, was used to obtain consistency of seated postures between subjects and between trials (Figure 1). The seat cushion used was constructed of three layers of $25-\mathrm{mm}$ (1 in) Sunmate(b) foam (type, soft blue, $5 \mathrm{lb} / \mathrm{ft}^{3}$ ).

Two OPMs were used to measure the pressure values under the buttock area. Four, $3 \times 4$ cell-matrix transducers ( 48 cells) were fixed to the seat surface so that their positions relative to a reference axis would remain constant. The transducer array was placed so that the ischial tuberosities of all subjects would fall on the back two arrays ( 24 cells). The front two transducer arrays were used only to ensure that the maximum 
pressure values actually occurred within the back two arrays.

The subjects were first positioned in the P1M (neutral) position on the $\mathrm{BPC}$, and pressure recordings were taken in the $\mathrm{P} 1 \mathrm{M}$ and all remaining eight standard positions (P1L to P7). Subjects were given a 15-minute free-movement period before each recording series to allow the seat foam and measurement equipment to reach steady state. Maximum pressure values, location of maximum values, mean average pressure values, and mean peak pressure gradients were all computed from the recorded data. Figure 2 defines the terms maximum, average, and peak pressure gradients. The subjects were not removed from the BPC between changes in body postures, thereby minimizing errors that could result from inaccuracies associated with reseating subjects (20). Successive pressure recordings were taken in one posture in order to conduct repeatability and variability checks on the pressure measurements. Calibration of the OPMs was done at the beginning of each trial and again at the end of those trials in which any comparatively high or low values were observed.

The forces acting tangentially to the seat surface (TIS) were measured in both the fore and aft directions. The seat surface (foam plus plywood substrate) was mounted on an aluminum substructure within the BPC. The seat was constrained by the load cells mounted at each end of the seat substructure so the seat would move not freely in the fore and aft directions. As a result, the load cells measured the horizontal reaction forces between the seat structure and the wheelchair frame, including the backrest, that tended to move the seat in the fore and aft directions. These forces were defined as the TIS or friction forces acting at the seat-body interface.

The TIS was measured simultaneously with the interface pressure in each of the nine standard sitting postures defined below. Mean values and standard deviations for both groups were computed and statistically analyzed. Significance was declared at the $\mathrm{p}=0.05$ level. The Student's $t$-test was used to test the paired and unpaired samples because of its increased sensitivity to errors associated with small samples (30).

\section{Instrumentation and calibration}

Pressure Measurement. The OPM was devel-

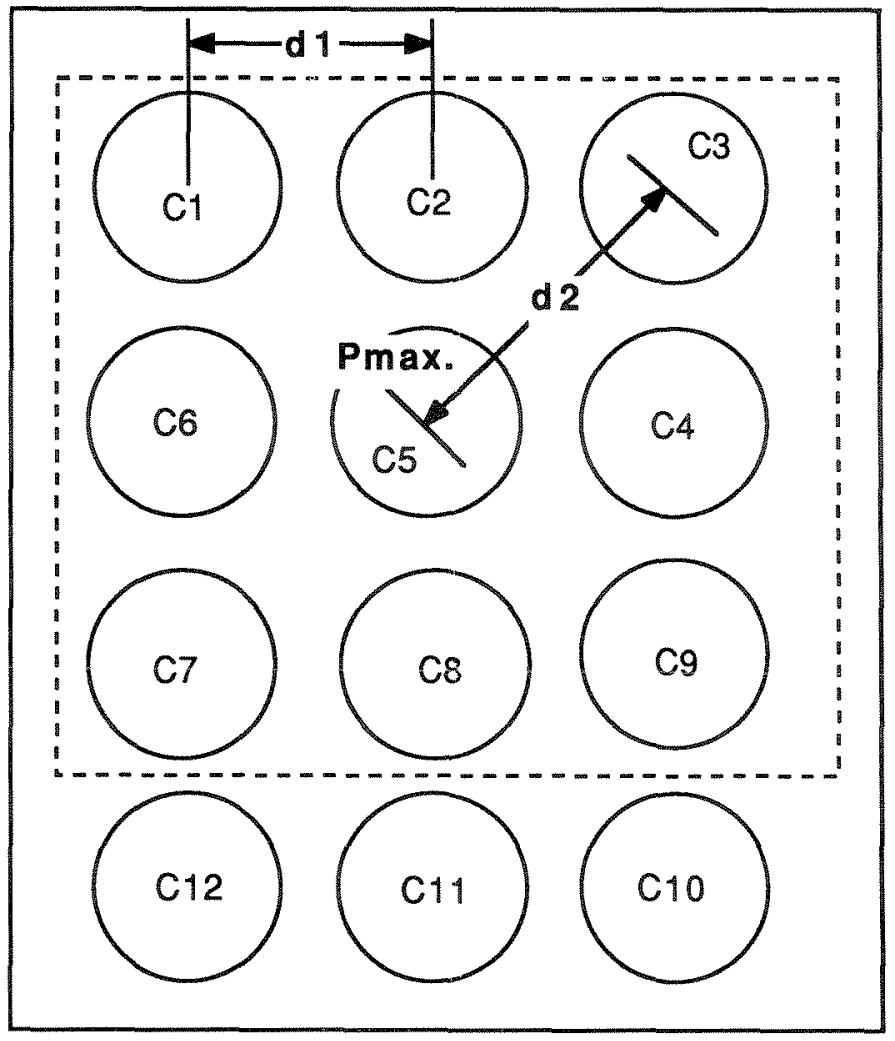

Average Pressure $=\frac{\operatorname{Sum}\left(C_{1} \ldots C_{12}\right)}{12}$

Maximum Pressure $=P \max \left(C_{1 . . . C 12}\right)$

\section{Peak Gradient $=$ Pmax $-P \min (C 1 \ldots . . C 9)$ d1 or $d 2$}

Figure 2.

Definitions of average, maximum, and peak pressure gradients.

oped at the Oxford Orthopedic Engineering Centre, Nuffield Orthopedic Centre, Oxford, England (21). The OPM, which works on the principle first described by O'Leary and Lyddy (22), consists of three basic components; the pneumatic transducer array, the monitor, and the calibration jig.

The transducers are supplied in either a $3 \times 4$ matrix configuration, a $1 \times 6$ matrix, or as single cells. An important feature of OPM development is that there are no electrical contacts necessary within the pneumatic transducer itself. Also, a transducer cell is only inflated when a pressure reading is taking place, thereby minimizing the perturbation effect on surrounding body-contact areas. The $3 \times 4$ matrix 
configuration used in this study is comprised of 12 20-mm-diameter cells mounted on $28-\mathrm{mm}$ centers. This matrix provides an effective measurement area of approximately $8,000 \mathrm{~mm}^{2}$. Each cell in the matrix is fed by a small-diameter flexible tube that plugs into the monitor manifold switch. The thickness of the deflated matrix is approximately $2-3 \mathrm{~mm}$. The OPM is powered by a $12 \mathrm{~V}(6-\mathrm{Ah})$ rechargeable $\mathrm{Ni}-\mathrm{Cd}$ battery. The stated pressure range is from 0 to $300 \mathrm{mmHg}$, with a resolution of $1 \mathrm{mmHg}$.

The calibration jig is composed of three components: a pressure gauge, a double-sided vinyl bladder, and a slotted compression box. The procedure involves placing the cell transducer matrix between the two halves of the inflatable bladder. The bladder/transducer assembly is then placed in the compression box, and the bladder is inflated to 100 $\mathrm{mmHg}$ as indicated by an interconnected external pressure gauge. The manifold of the OPM is then rotated through the various cell settings, and any variation from the $100-\mathrm{mmHg}$ calibration value is noted. A calibration setting on the side of the OPM allows adjustment of the recorded values to the $100-\mathrm{mmHg}$ calibration value. This procedure permitted calibration of the two OPM units used to within \pm 3 percent of the $100-\mathrm{mmHg}$ calibration level across the cell matrix. This level of accuracy was achieved consistently throughout the recording session. Calibration data published by the developers (21) show a maximum deviation from linearity of 3 percent over the optimum range of $0-250 \mathrm{mmHg}$.

Rationale for the Selection of the Oxford Pressure Monitor. A review of previous work on qualifying pressure distribution revealed a wide selection of possible approaches. Each approach is not without its limitations. In general, miniature electronic transducers proved difficult to position accurately, are expensive, and are not readily available in matrix configurations that could be applied to the needs of this study. Also, reports of hysteresis problems, contamination by tangential forces, and electrical interference discouraged use of miniature electronic devices.

Preliminary trials were conducted with the TIPE device first developed at the Texas Institute for Rehabilitation Research in Houston, Texas (15). The device uses a $12 \times 12$ pneumatic transducer matrix, which is attractive because of the large surface area it covers. However, the maximum pressure of $150 \mathrm{mmHg}$ was found inadequate. Also, consistent problems were encountered with the electrical contacts within the transducers. And finally, no calibration method is provided with the TIPE system, making it difficult to conduct routine calibrations.

Suggestions have been made that accuracy is improved when a single transducer cell is attached directly to the skin over an ischial tuberosity, rather than placing an array on the test surface. The radiographic results show that the ischial tuberosities shift approximately $4 \mathrm{~cm}$ during the complete range of movements studied. Therefore, the single-cell skin method is not appropriate for experiments in which large changes in trunk positions are to be studied.

Finally, 3 years of previous experience had shown the OPM to be a reliable and durable device that provides reasonably accurate results within known limitations. Linearity and variability tests have been done and published by the developers $(20,21)$. The OPM is commercially available, and for this and the above reasons it was chosen as the most appropriate pressure-measurement system to use in the study. Furthermore, the fundamental approach of using relative rather than absolute values with the same seat cushion means that the errors associated with the OPM at least will be consistent and therefore largely self-canceling (23).

Shear Measurement. The load cells used were Sensortronics, model 60040, which is a low-profile bidirectional version that is produced in a variety of load capacities. The data-acquisition system used was a Metrabyte DAS-16 multifunctional high-speed analog-digital (A/D) I/O expansion board for the IBM PC computer. The front-end signal amplification and conditioning are done using a commercial unit from Action Instruments, model AP4051. The BASIC software program combined with the Metrabyte $\mathrm{A} / \mathrm{D}$ board permitted calibration and adjustment of the baseline settings for the load cells before each run. Calibration of the load cells was done using a spring scale. A plot of the force-versusvoltage output indicated a linearity of approximately 2 percent within the operating range of the scale $(0-25 \mathrm{lb}, 0-11.3 \mathrm{~kg})$. Tests were done to determine the friction force in the linear bearings, which in turn was used to adjust the recorded values of the load cells. Regression computations were necessary because the friction values varied slightly with body weight. 
Journal of Rehabilitation Research and Development Vol. 29 No. 4 Fall 1992

\section{Definitions of standardized postures}

The following definitions of the standard postures are illustrated in Figures 3, 4, and 5 .

P1M-Position: Defined as the posture in the BPC with the pelvis placed as far posteriorly on the seat as possible, trunk and pelvis on the midline, and head in contact with the headrest. The seat surface is horizontal with the backrest reclined $10^{\circ}$ to the vertical $\left(100^{\circ}\right)$. Arms are comfortably placed on the thighs, and footrests are adjusted to take approximately 10 percent of the body weight.

P1L-Trunk Bending-Left: Defined as the posture in
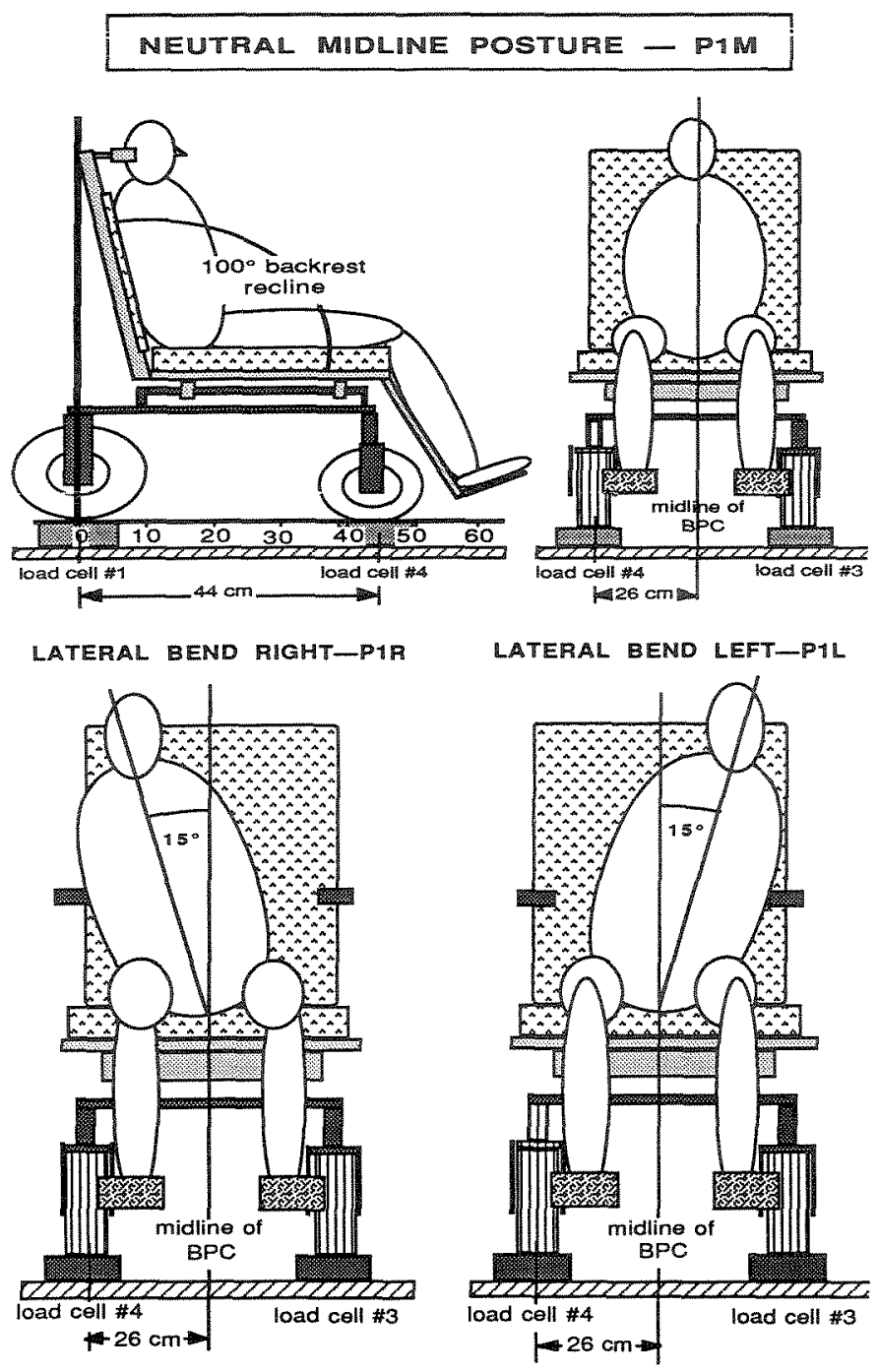

Figure 3.

Definitions of postures P1M, P1L, and P1R.

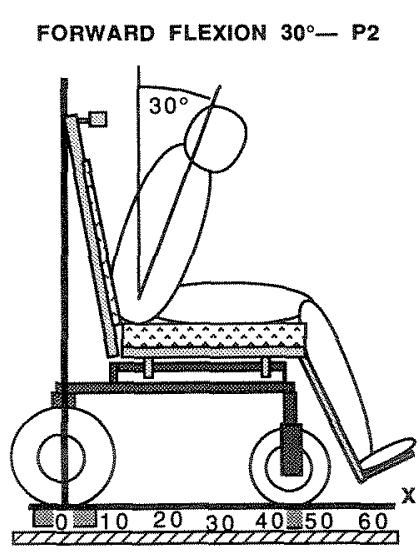

FORWARD FLEXION $50^{\circ}-P 3$

BACKREST RECLINE $110^{\circ}-$ P4
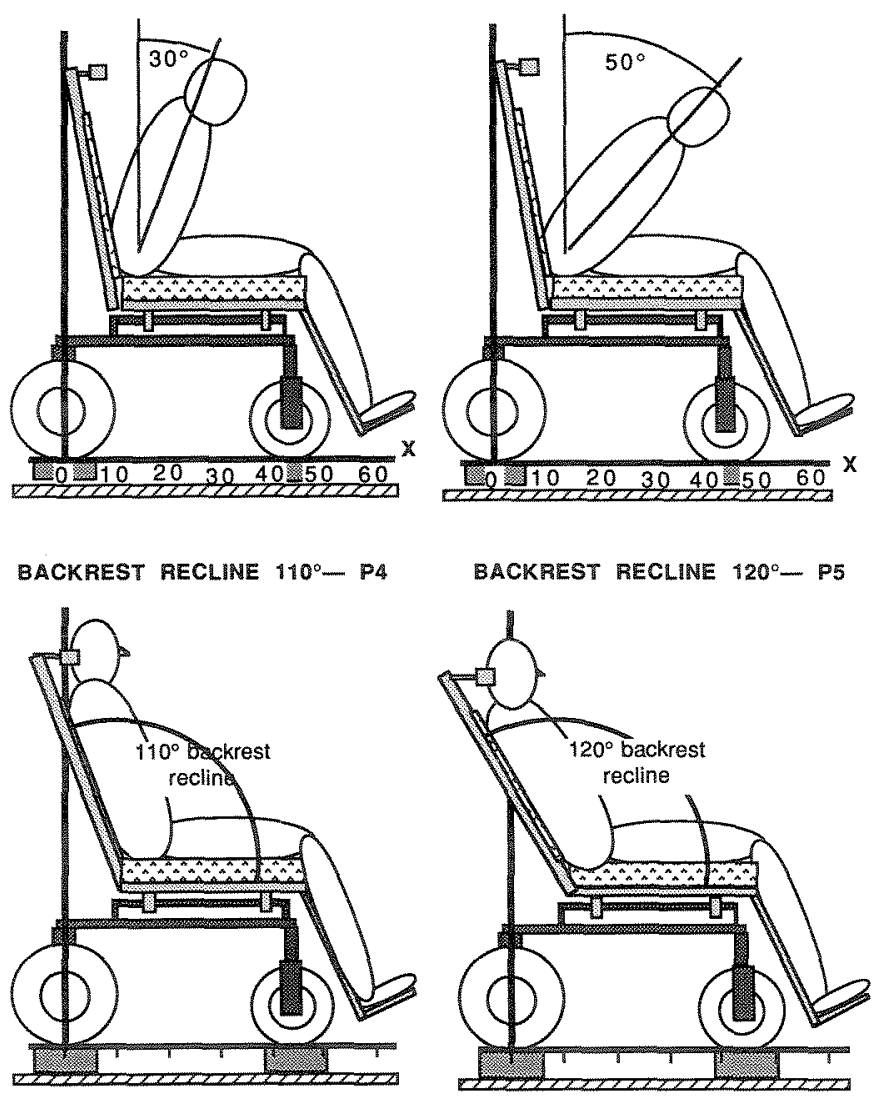

Figure 4.

Definitions of postures P2, P3, P4, and P5.

the BPC the same as P1M above, except that the trunk is flexed to the left until the left side contacts the elevated armrests (approximately $15^{\circ}$ of lateral trunk flexion).

PIR-Trunk Bending-Right: Defined as the posture in the BPC the same as $P 1 M$, except the trunk is flexed to the right side.

P2-Forward Trunk Flexion $30^{\circ}$ : Defined as the posture in the BPC the same as $\mathrm{P} 1 \mathrm{M}$, except the head and trunk are flexed forward $30^{\circ}$ along the $\mathrm{A} / \mathrm{P}$ midline.

P3-Forward Trunk Flexion $50^{\circ}$ : Defined as the posture in the BPC the same as $\mathrm{P} 1 \mathrm{M}$, except the head and trunk are flexed forward $50^{\circ}$ along the $\mathrm{A} / \mathrm{P}$ midline.

P4-Back Recline $110^{\circ}$ : Defined as the posture in the $\mathrm{BPC}$ the same as P1M, except the backrest is 


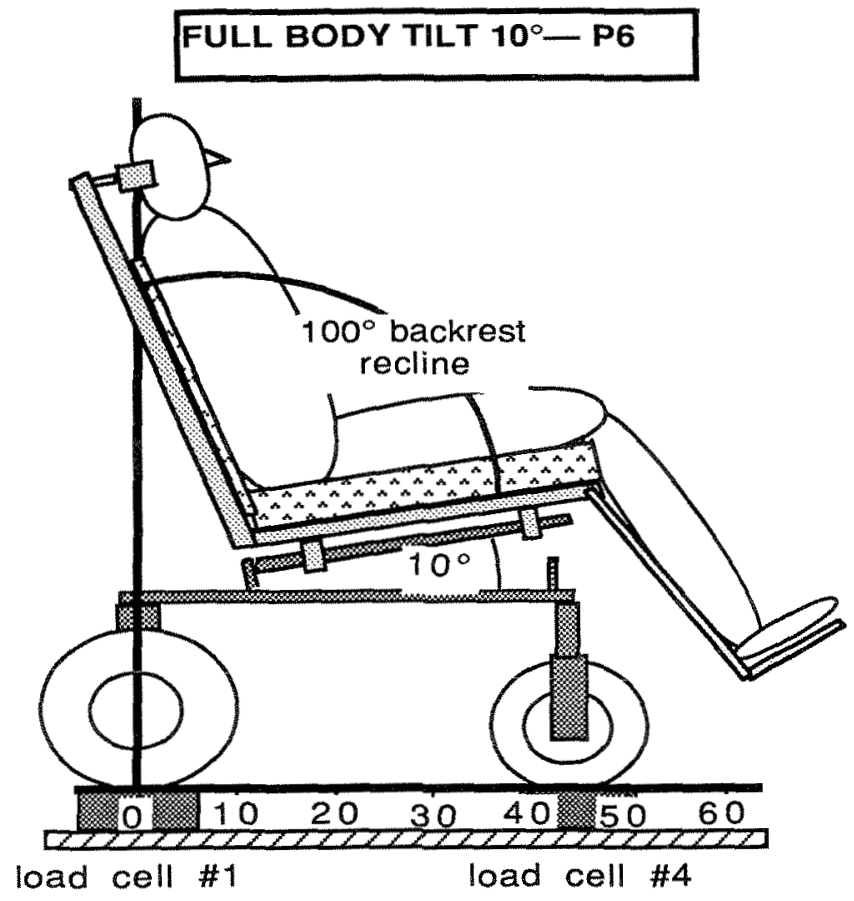

FULL BODY TILT $20^{\circ}-\mathrm{P7}$

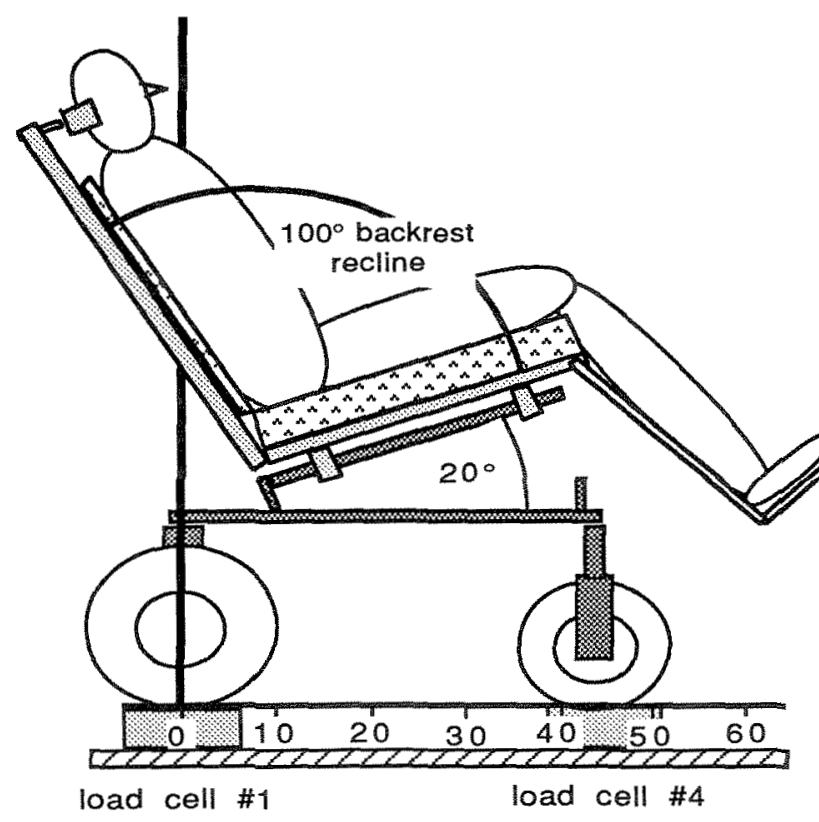

Figure 5.

Definitions of postures $\mathbf{P 6}$ and $\mathbf{P 7}$.

reclined to the $110^{\circ}$ position.

P5-Back Recline $120^{\circ}$ : Defined as the posture in the $\mathrm{BPC}$ the same as P1M, except the backrest is reclined to the $120^{\circ}$ position.

P6-Body Recline $10^{\circ}$ : Defined as the posture in the
BPC the same as P1M, except the whole seat assembly (seat and back) is tilted $10^{\circ}$ in space.

P7-Body Recline $20^{\circ}$ : Defined as the posture in the BPC the same as P1M, except the whole seat assembly (seat and back) is tilted $20^{\circ}$ in space. 
Journal of Rehabilitation Research and Development Vol. 29 No. 4 Fall 1992
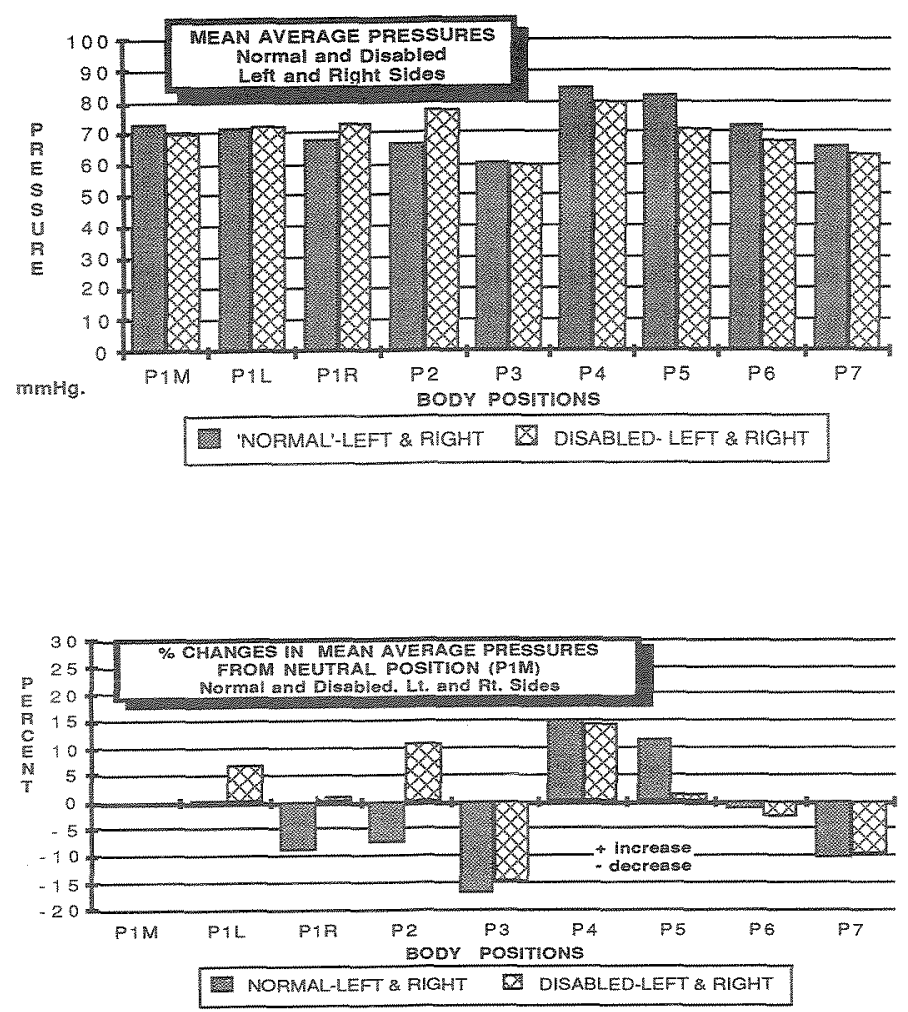

Figure 6.

Results of pressure measurements averaged over 24 transducers. Upper plot shows the average values for both groups. Lower plot shows the percentage of change in the values from those in the neutral posture (P1N) as a result of changes in posture.

\section{RESULTS}

\section{Pressure study}

Figures 6,7 , and 8 graphically portray the results of the average, maximum, and peak pressure gradients for each study group. These results may be summarized as follows:

1. Average pressure distribution between populations is affected insignificantly by alterations of sitting posture. Forward flexion of the trunk causes the largest decrease within both groups from the average pressures in the neutral position. On average, a reduction of approximately 15 percent from the values in the neutral position occurs at $50^{\circ}$ of trunk flexion (P3). However, the SCI group experiences an increase of approximately 10 percent at $30^{\circ}$ of forward flexion (P2) before a reduction begins to take place.

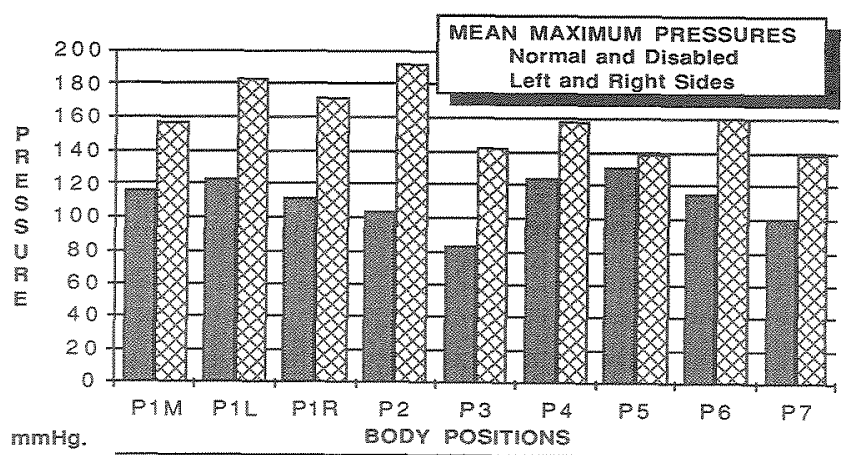

WOAMAL-LEFT \& RITT D DSABLED-LEFT \& RIOHT

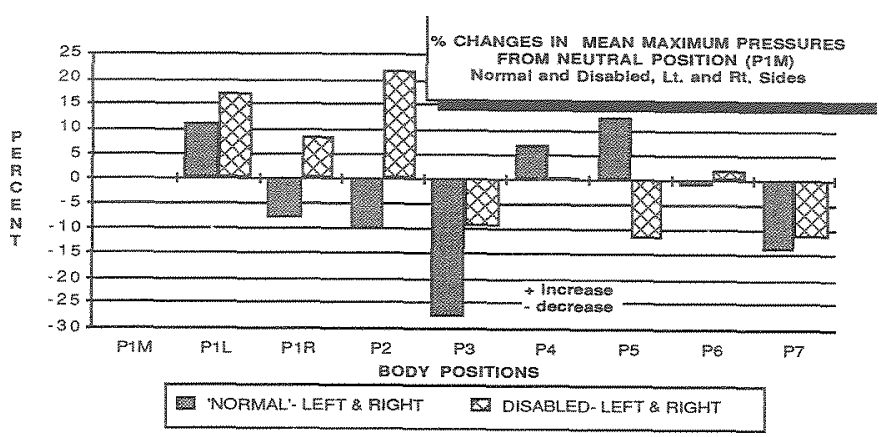

Figure 7.

Results of maximum pressure measurements. Upper plot shows maximum pressures for both groups in nine postures. Lower plot shows the percentage of change of maximum values from those recorded in the neutral position (1M).

2. Mean maximum pressures of individuals with SCI are significantly higher than nondisabled individuals in all nine sitting postures studied. In the neutral posture, on average, the maximum pressure for a person with $\mathrm{SCI}$ is 26 percent higher. The differences range from a low of 6 percent in the P5 position to a high of 46 percent in the $\mathbf{P} 2$ position.

3. The maximum pressures can be reduced by postural changes from those values occurring in the neutral $\mathbf{P} \mathbf{I M}$ posture. These reductions are: lateral trunk bending $15^{\circ}(-32$ to -38 percent), forward flexion to $50^{\circ}$ ( -9 percent), backrest recline to $120^{\circ}(-12$ percent $)$, and full-body tilt to $20^{\circ}$ ( -11 percent).

4. Alterations to sitting postures cause similar changes to the $\mathrm{A} / \mathrm{P}$ location of the maximum pressure $\left(\mathrm{P}_{\mathrm{mx}}\right)$ for both disabled and nondisabled. In the neutral posture, forward trunk flexion of $30^{\circ}$ and of $50^{\circ}$ results, on the 

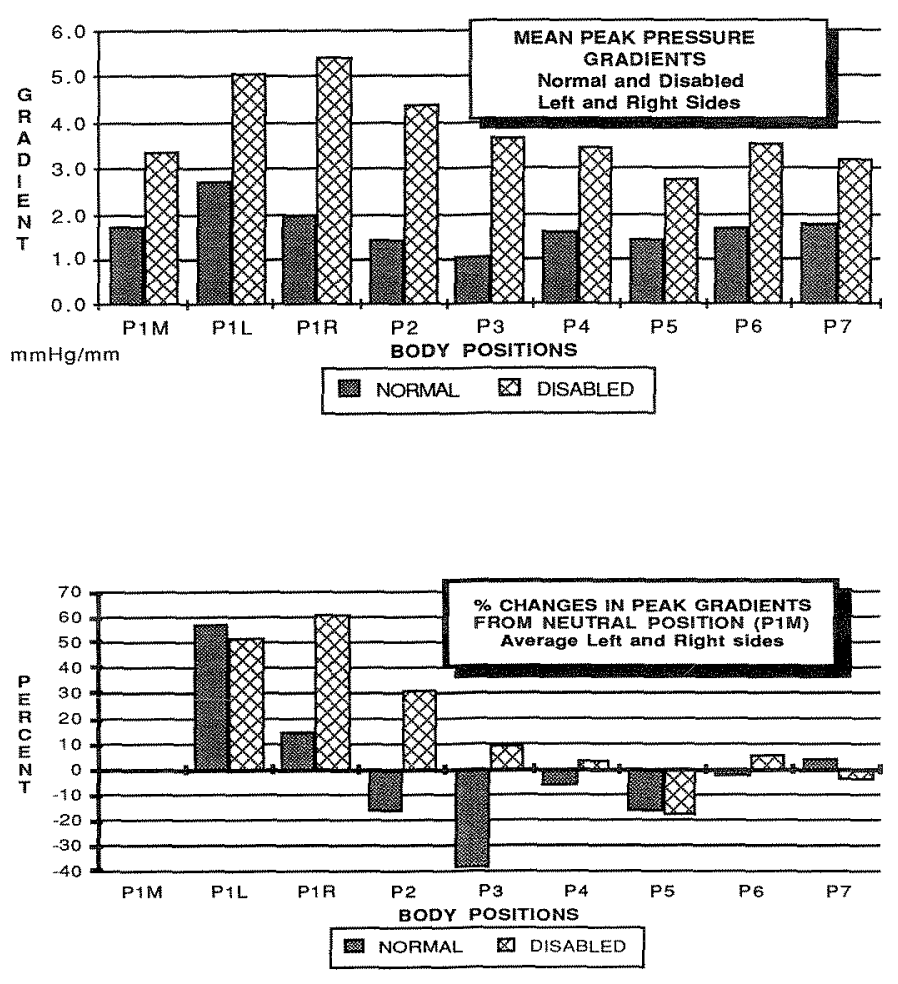

Figure 8.

Computed results of peak pressure gradients. Upper plot shows the peak gradient for both groups in each of the nine postures. Lower chart indicates the percentage of change in the peak gradients from the neutral position value (P1M) that results from changes in seated posture (P1L-P7).

average, in a posterior shift of 2.4 and $2.7 \mathrm{~cm}$, respectively. The largest posterior shift of $6 \mathrm{~cm}$ occurs with the backrest reclined to $120^{\circ}$ (P5).

5. On average, individuals with SCI have peak pressure gradients that are 1.5 to 2.5 greater than nondisabled people (Figure 8). Among the postures studied, maximum reduction of the peak gradients from those measured in the neutral posture occurs after backrest recline to $120^{\circ}$ (P5, -8 percent). Large increases in pressure gradients can occur during lateral bending (50-60 percent) or during forward trunk flexion (10-60 percent).

\section{Tangential shear study}

Figure 9 graphically depicts the results of the surface shear-force study. The results may be summarized as follows:
1. TIS acts at the body-seat surface in all nine postures studied.

2. With respect to the neutral posture $(\mathbf{P} 1 \mathbf{M})$, maximum reductions of TIS force occur upon forward trunk flexion of $50^{\circ}$ (P3) $(-133$ percent or a reversal of 33 percent) and upon full-body tilt to $20^{\circ}$ ( -85 percent). Extrapolation of these results suggests that full-body tilt to approximately $25^{\circ}$ reduces the TIS to near zero $(-100$ percent). Further tilting causes a reversal and a gradual increase in TIS in the opposite direction.

3. Compared with the values in the neutral posture, backrest recline postures, P4 and P5, cause an increase in the TIS by 7 percent and 25 percent, respectively.

\section{DISCUSSION AND IMPLICATIONS}

The average pressure distribution across the critical buttock area varies little between nondisabled persons and individuals with paralytic injuries. Furthermore, typical alterations in postures assumed while sitting in a wheelchair have minimal effect on the average pressure distribution. Forward flexion of the trunk to $30^{\circ}$ is required to obtain a reduction of about 15 percent from the average pressure values in the neutral posture.

People with SCI have maximum pressures that are significantly higher than nondisabled individuals in most postures typically assumed in a wheelchair. The differences in mean maximum pressure range from a minimum of 6 percent in the backrest recline $120^{\circ}$ posture to a maximum of 45 percent in the forward flexed posture to $30^{\circ}(\mathbf{P} 2)$. The difference in the neutral posture (P1M) is about 25 percent. It is concluded that these inherent differences in mean maximum pressures are largely due to asymmetrical ischial loading caused by spinal/pelvic deformities and atrophy of tissue over the ischiae.

Changes in posture can effectively reduce the maximum pressures of SCI people from those values that are present in their neutral sitting postures. On average, recline of the backrest to $120^{\circ}$ reduces the neutral values by 12 percent as does the full-body tilt to $20^{\circ}$ (11 percent). Forward trunk flexion to $50^{\circ}$ yields a reduction of 9 percent. Lateral bending to $15^{\circ}$ reduces the neutral values by $30-40$ percent on the unweighted side. 

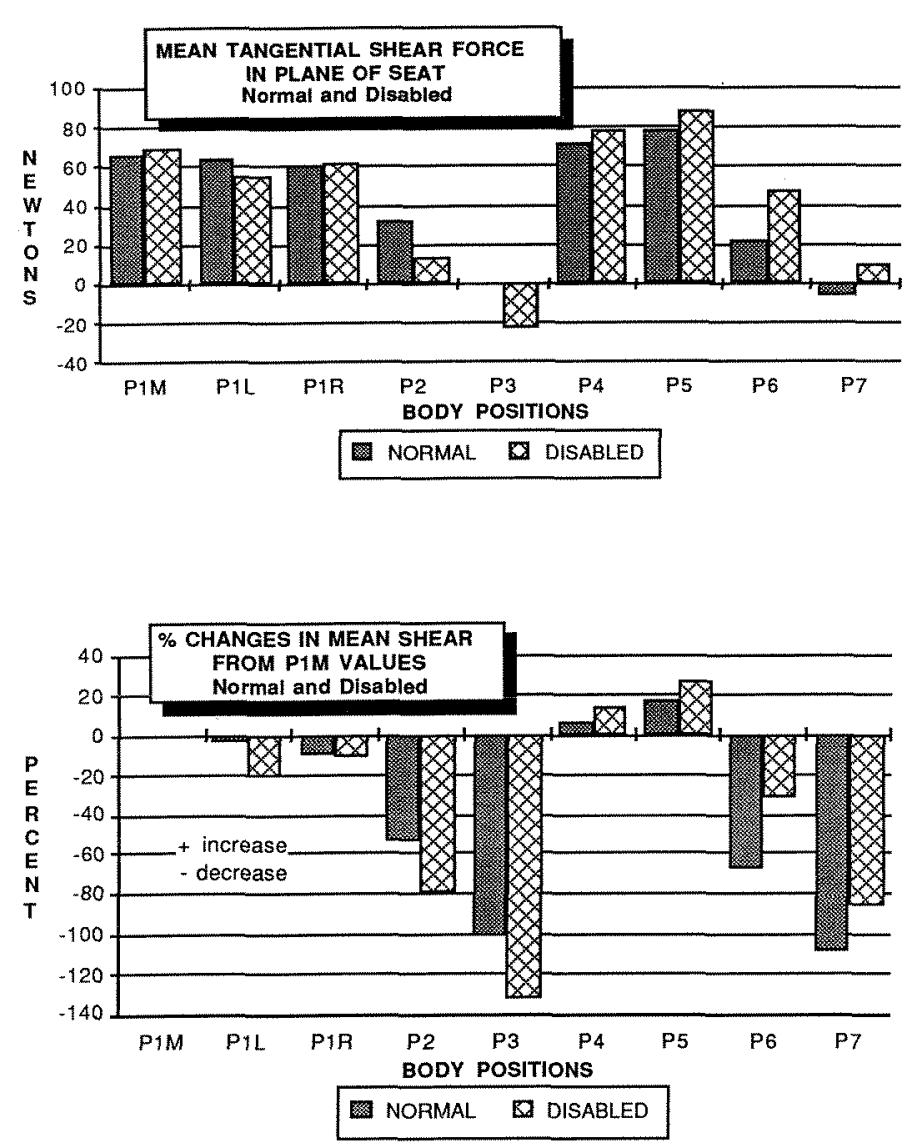

Figure 9.

Results of tangential shear force (fore and aft) acting on buttock tissues in plane of seat. Upper plot shows values for both groups in nine study postures. Lower plot indicates the percentage of change that can take place in the surface shear values from those values recorded in the neutral position (P1M) as a result of posture change (P1L-P7).

The implications of these findings are possibly more important from a research perspective. They suggest that caution must be exercised when using nondisabled subjects and absolute pressure values to make judgments about the pressure-distribution characteristics of commercial cushions or generic seating materials. Also, shape and pressure contours derived from nondisabled subjects can yield profiles that are misleading regarding the characteristics of paralytic buttock contours.

A peak pressure gradient has been defined as the maximum gradient between any two adjacent pressure-recording cells. According to the definition of the peak gradients used in this study, the peak gradients are directly related to the maximum pressure. Therefore, the peak gradients are also inherently higher for the SCI group in all sitting postures. On average, peak gradients are higher by 1.5-2.5 times, depending on the assumed posture. These values can be lowered by reducing maximum pressures through altering posture.

The implications from these findings are several. First, shear-stress theory implies that the higher the force gradient between two points the higher the induced shear stress. The body-support interface is a complex arrangement of bony prominences, overlying tissue, clothes, transducer, cushion cover, and supporting materials, all of which are subjected to both normal and shear loading. Therefore, it is very difficult to make accurate determinations as to the exact nature of the shear stresses in the tissues. However, it seems reasonable to assume that if high pressure gradients are recorded by the transducer matrix, these gradients should, in some manner, be related to elevated shear stresses in the supporting tissues. Second, if shear stress, acting in combination with high normal loads, presents a critical combination of events, as proposed by Bennett et al. (9) and Chow and Odell (29), then knowledge of cushion materials and postures that minimize these occurrences is vitally important. It follows that a simple measurement of maximum pressure in one static posture may not yield the information necessary to minimize the critical combination of normal pressure and shear pressure interacting at a pelvic location under high risk of ulceration.

Finally, it is evident that sitting posture and body orientation in space can have a profound effect on body-seat interface variables. Although this study does not clarify the manner in which shear and normal stresses interact with postural change to place the buttock tissues at increased risk, it does suggest that posture is a factor that deserves increased research and clinical attention. In particular, clinicians should be more aware of the potential effects of posture and postural changes when evaluating and recommending pressure-management regimes.

\section{ACKNOWLEDGMENTS}

This work was sponsored by the Crippled Children's Hospital Foundation, Memphis, TN. The author gratefully acknowledges the UTREP staff contributions by Stan Cronk, Glen Ellis, and Beverly Wilson. 


\section{REFERENCES}

1. Clark MO, Barbenel JC, Jordan MM, Nicol SM. Prevalence of pressure sores. Nurs Times 1978;74:363.

2. Young JS, Burns PE. Pressure sores and the spinal cord injured model systems. Sci Dig 1981;3(9):18-25.

3. Young JS, Burns PE. Pressure sores and the spinal cord injured; part two: model system. Sci Dig 1981;3(11):2648.

4. Kosiak M. Etiology of decubitus ulcers. Arch Phys Med Rehabil 1961;19-29.

5. Brand PW. Patient monitoring. In: Kenedi RM et al., editors. Bed sore biomechanics. London: Macmillan, 1976: 183-4.

6. Daniel RK, Priest DL, Wheatley DC. Etiologic factors in pressure sores: an experimental model. Arch Phys Med Rehabil 1981;62:492-8.

7. Nola GT, Vistnes LM. Differential response of skin and muscle in the experimental production of pressure sores. Plast Reconstr Surg 1980;66(5):728-33.

8. Patterson RP. Is pressure the most important parameter? In: Decubitus ulcers. Report of symposium. Washington (DC): Paralyzed Veterans of America, 1984.

9. Bennett L, Kavner D, Lee BK, Trainor FA. Shear vs. pressure as causative factors in skin, blood flow occlusion. Arch Phys Med Rehabil 1979;60:309-14.

10. Hyman WA, Artigue RS. Studies of soft tissue metabolism. TIRR Rehabil Eng Rep 1976:26-59.

11. Trandel RS, Lewis DW. A small pliable humidity sensor, with special reference to the prevention of decubitus ulcers. J Am Geriatr Soc 1975;23(7):322-6.

12. Fisher SV, Patterson RP. Long-term pressure recordings under the ischial tuberosities of tetraplegics. Paraplegia 1983; 21:99-106.

13. Hobson DA. Seated posture and its implications on pressure sore management. In: Decubitus ulcers. Report of symposium. Washington (DC): Paralyzed Veterans of America, 1984.

14. Zacharkow D. Wheelchair posture and pressure sores. Springfield (IL): Charles C. Thomas, Publisher, 1984.

15. Garber SL, Krouskop TA. Body build and its relationship to pressure distribution in the seated wheelchair patient.
Arch Phys Med Rehabil 1982;63(1):17-20.

16. Crenshaw BS, Vistnes LM. A decade of pressure sore research: 1977-1987. J Rehabil Res Dev 1989;26(1):63-74.

17. Mooney V, Einbund J, Rogers JE, Stauffer ES. Comparison of pressure distribution qualities in seat cushions. Bull Prosthet Res 1971 Spr;10-15:129-43.

18. Fernie GR. Biomechanical aspects of the aetiology of decubitus ulcers on human patients [dissertation]. Glasgow: Univ. of Strathclyde, 1973.

19. Ferguson-Pell MW. Design criteria for the measurement of pressure at the body support surfaces. Eng Med 1980;9:209-14.

20. Bader DL. Interface pressure measurement. CARE Sci Pract 1982;1(3):22-4.

21. Bader DL, Hawken MB. Pressure distribution under the ischium of normal subjects. J Biomed Eng 1986;8:353-7.

22. O'Leary JP, Lyddy TE. A nondistorting transducer for measuring pressure under load-bearing tissue. Proceedings of the 5th Annual Conference on Systems and Devices for Disabled, 1978.

23. Reddy NP, Palmieri V, Cochran GV. Evaluation of transducer performance for buttock-cushion interface pressure measurements. J Rehabil Res Dev 1984;21(1):4350.

24. Guthrie L. The effect of transducer curvature on interface pressure readings. Proceedings of the 14th Annual RESNA Conference; 1991 June 21-26; Kansas City (MO). Washington (DC): RESNA Press, 1991:138-9.

25. Guttmann L. The prevention and treatment of pressure sores. In: Kenedi RM, Cowden JM, Scales JT, editors. Bed sore biomechanics. London: Macmillan, 1976:153-9.

26. Reichel SM. Shearing force as a factor in decubitus ulcers in paraplegics. J Am Med Assoc 1958;166(7):762-3.

27. Dinsdale SM. Decubitus ulcers: role of pressure and friction in causation. Arch Phys Med Rehabil 1974;55:147-52.

28. Neumark OW. Deformation, not pressure, is the prime cause of pressure sores. CARE Sci Pract 1981a;1(1).

29. Chow WW, Odell EI. Deformations and stresses in soft body tissues of a sitting person. J Biomech Eng 1978;100:79-87.

30. Speigel MR. Probability and statistics. Shaum's outline series. New York: McGraw-Hill, 1975. 